\title{
Isolasi dan Karakterisasi Selulosa Mikrokristal dari Ampas Tebu (Saccharum Officinarum L.)
}

\section{Isolation and Characterization of Microcrystalline Cellulose from Bagasse (Saccharum officinarum L.)}

\author{
Desy Nawangsari* \\ Fakultas Kesehatan, Program Studi Sarjana Farmasi, Universitas Harapan Bangsa \\ *email: desynawangsari@uhb.ac.id
}

Received: 01 November 2019; Accepted: 26 Desember 2019; Published: 27 Desember 2019

\begin{abstract}
Abstrak
Selulosa mikrokristal merupakan hasil isolasi dari alfa selulosa. Tanaman berkayu umumnya menjadi sumber pembuatan selulosa mikrokristal. Salah satu bahan alam yang dapat dimanfaatkan untuk membuat selulosa mikkrokristal adalah ampas tebu (Saccharum officinarum L.). Ampas tebu (Saccharum officinarum L.) mengadung 37,65\% selulosa yang dapat diisolasi dengan tahapan delignifikasi menggunakan larutan basa, proses pemutihan serta hidrolisis alfa selulosa dengan pemanasan suhu tinggi menggunakan larutan asam encer. Rendemen selulosa mikrokristal dari ampas tebu 26,03\% dan memenuhi karakterisasi berdasarkan literatur.
\end{abstract}

Kata Kunci: selulosa mikrokristal, ampas tebu, isolasi

\section{Abstract}

Microcrystalline cellulose is the result of isolation from alpha cellulose. Woody plants are generally the source of microcrystalline cellulose production. One of the natural ingredients that can be used to make microcrystalline cellulose is bagasse (Saccharum officinarum L.). Bagasse contains $37.65 \%$ of cellulose which can be isolated by the delignification stage using a base solution, the process of bleaching and hydrolysis of alpha cellulose by high temperature heating using dilute dilute acid. The yield of microcrystalline cellulose from bagasse $26.03 \%$ and fulfilling the characterization based on the literature.

Keywords: microcystalline cellulose, bagasse, isolation

\section{PENDAHULUAN}

Indonesia merupakan negara yang memiliki kekayaan sumber daya alam. Keragaman sumber daya alam tersebut berkorelasi langsung dengan keragaman kimia yang memiliki potensi yang sangat besar bagi pengembangan obat (Kementerian Kesehatan, 2013). Tebu merupakan salah satu tanaman yang memiliki potensi tersebut. Di Indonesia tebu banyak dibudidayakan di pulau Jawa dan Sumatra. Ampas tebu mengandung selulosa 45,96\% (Septiyani (2011). Selulosa dari ampas tebu yang melalui proses isolasi dapat dimanfaatkan untuk pembuatan selulosa mikrokristal (Bhimte dan Tayade, 2007;
Ohwoavworhua dan Adelakun, 2009; Sun et al., 2004).

Dalam bidang farmasetik, selulosa mikrokristal dimanfaatkan sebagai bahan pengisi pada sediaan tablet. Keuntungan menggunakan selulosa mikrokristal yaitu meningkatkan kemampuan kekompakan tablet dari campuran kompresi. Selulosa mikrokristal juga mampu meningkatkan sifat alir masa cetak tablet (Carlin, 2008). Karakter yang dimiliki oleh selulosa mikrokristal tersebut sangat membantu dalam proses pencetakan tablet dengan menggunakan metode kempa langsung yang memerlukan peningkatan kualitas dan konsistensi dari 
bahan awal termasuk eksipien (Patel, Kaushal and Bansal, 2006).

Tujuan penelitian ini menghasilkan selulosa mikrokristal dari ampas tebu serta melakukan karakterisasi terhadap selulosa mikrokristal dari ampas tebu.

\section{METODE PENELITIAN}

Alat

Alat-alat yang digunakan dalam penelitian ini adalah timbangan digital (Kenko), gelas beaker, kompor listrik, gelas ukur, batang pengaduk, kertas saring, oven.

Bahan

Bahan-bahan yang digunakan dalam penelitian ini adalah ampas tebu diperoleh dari pedagang es tebu disekitar kampus Harapan Bangsa, asam asetat, natrium hidroksida, natrium hipoklorit, asam klorida.

\section{Preparasi Bahan Baku Ampas Tebu}

Ampas tebu diperoleh dar pedagang es tebu di sekitar kampus Universitas Harapan Bangsa Purwokerto, Jawa Tengah. Ampas tebu yang diperoleh disortasi dan dicuci berulang hingga bersih dengan air mengalir, kemudian dilakukan pemotongan sehingga di peroleh ukuran yang lebih kecil. Selanjutnya ampas tebu dikeringkan dengan oven pada suhu $50^{\circ} \mathrm{C}$ selamat 72 jam sampai diperoleh ampas tebu yang kering. Tujuan preparasi ini adalah untuk memudahkan isolasi selulosa yang terkandung dengan memperkecil ukuran, meningkatkan luas permukaan kontak, memecah ikatan kimia pada rantai molekul yang panjang sehingga diharapkan mendapatkan hasil rendemen yang optimal.

\section{Isolasi alfa selulosa}

Isolasi $\alpha$-selulosa dari serat tumbuhan dilakukan dengan metode pemanasan alkali. Ampas tebu dididihkan dengan menggunakan asam asetat $0,1 \mathrm{~N}$ dengan perbandingan sampel terhadap pelarut 1:20 tahapan ini disebut pra-hidrolisis (Mohamad Haafiz et al., 2013). Prahidrolisis dilakukan selama satu jam dengan suhu $105^{\circ} \mathrm{C}$. Setelah itu sampel dipisahkan dari pelarutnya dengan cara penyaringan dan pemerasan kemudian sampel dibilas berulang hingga $\mathrm{pH}$ netral (Umar,
2011). Tahap ini bertujuan untuk memperlunak bahan dan mempercepat pemutusan ikatan pentose (hemiselulosa) (Thakur, 2014). Tahap isolasi dilanjutkan dengan pemanasan alkali menggunakan Natrium Hidroksida $25 \%$ b/v pada suhu $105^{\circ} \mathrm{C}$ dan dididihkan selama satu jam. Perbandingan sampel dengan Natrium Hidoksida adalah 1:20 (Mohamad Haafiz et al., 2013). Pada proses ini terbentuk pulp atau bubur selulosa dimana $\alpha$-selulosa terisolasi sebagai residu. Alfa selulosa merupakan senyawa yang tidak larut dalam $\mathrm{NaOH}$ atau basa kuat, hal ini digunakan untuk mendegradasi polimer lignin yang kemudian akan larut ke dalam air. Pada proses ini terbentuk pulp berwarna coklat pekat yang mengendap di dalam larutan natrium hidroksida. (Hamisan et al., 2009). Kemudian serat tanaman dipisahkan kembali dari pelarutnya dengan cara penyaringan dan pemerasan, ampas tebu dibilas sampai $\mathrm{pH}$ kembali netral. Pulp yang diperoleh dicuci berulang hingga $\mathrm{pH}$ 6-7. Tahap berikutnya yaitu bleaching. Tujuan dari tahap ini adalah untuk menghilangkan sisa lignin dan karbohidrat yang tidak terpisah sempurna dalam pulp. Proses bleaching akan membuat warna pulp

menjadi lebih cerah atau putih. Proses ini dilakukan dengan cara merendam serat tanaman dalam larutan $\mathrm{NaClO}$ dengan perbandingan sampel dan pelarut 1:8 selama 15-20 menit (Mohamad Haafiz et al., 2013). Pada saat perendaman sampel yang semula

terapung di dalam larutan berwarna putih kecoklatan kemudian menjadi putih kekuningan dan perlahan menjadi putih seluruhnya dan turun di dasar permukaan. Hal ini disebabkan karena produk teroksidasi menjadi suatu bahan yang mudah larut dalam air. Larutan disaring dan residu dibilas dengan aquades secara berulang hingga $\mathrm{pH}$ kembali netral. Selanjutnya pulp dikeringkan dengan menggunakan oven $50^{\circ} \mathrm{C}$ selama $12-24$ jam (Carlin, 2008). Pulp kering yang diperoleh disebut sebagai $\alpha$-selulosa (Mersa, 2008). 


\section{Pembuatan Selulosa mikrokristal}

Pulp kering hasil oven berupa $\alpha$-selulosa mengalami hidrolisis parsial atau depolimerisasi menjadi selulosa mikrokristal melalui proses hidrolisis pemotongan rantai panjang selulosa dengan cara direndam dalam larutan $\mathrm{HCl} 2,5 \mathrm{~N}$ direaksikan pada suhu $105^{\circ} \mathrm{C}$ selama 15 menit, perbandingan sampel dengan pelarut adalah 1:20 (Ohwoavworhua and Adelakun, 2005). Selama proses hidrolisis terjadi pemisahan secara parsial pada penyususn mikrofibril selulosa dimana bentuk amorf akan putus dan meninggalkan bentuk kristalin yaitu daerah molekul selulosa yangtersusun teratur (Ma, Chang and $\mathrm{Yu}$, 2008). Tujuan dari proses ini agar $\alpha$-selulosa yang merupakan selulosa berantai panjang dengan derajat polimerisasi yang tinggi yaitu 600-1500 dihidrolisis sehingga terjadi pemotongan polimer menjadi ukuran yang lebih kecil (mikro) dengan derajat polimerisasi yang kecil pula dimana $\mathrm{n} \approx 220$ sehingga dihasilkan selulosa mikrokristal (Håkansson and Ahlgren, 2005).

Residu selulosa mikrokristal yang didapat dibilas dengan aquadest sampai $\mathrm{pH}$ netral dan disaring dengan menggunakan kertas saring. Selanjutnya dilakukan tahap penyaringan, pengeringan, dan pengayakan dengan menggunakan teknologi spray dry sesuai yang tercantum oleh Handbook of Pharmaceutical Excipients (Rowe, Sheskey and Quinn, 2009)

\section{Karakterisasi Selulosa Mikrokristal}

Serbuk selulosa mikrokristal hasil isolasi dari ampas tebu di karakterisasi dan dibandingkan dengan literatur Handbook of Pharmaceutical Eksipient. Adapun pengujian yang dilakukan meliputi:

1. Kadar air

Pengujian kadar air dilakukan dengai alat moisture balance. Selulosa mikrokristal ditimbang 10 gram dan dimasukan pada spaciment yang tersedia pada alat moisture balance.

2. Penentuan $\mathrm{pH}$

Penetuan $\mathrm{pH}$ dilakukan dengan $\mathrm{pH}$ meter digital. $\mathrm{pH}$, dengan cara mendispersikan selulosa mikrokristal $15 \%$ kedalam akuadest, selanjutnya $\mathrm{pH}$ meter digital dimasukan kedalam larutan tersebut dan dibaca $\mathrm{pH}$ pada alat. (Thoorens, et.al., 2015).

3. Bilangan Permanganat

Berdasarkan SNI 0494:2008 sebanyak 0,1 gram selulosa mikrokristal dimasukkan ke dalam gelas beaker, ditambahkan $70 \mathrm{~mL}$ aquadest, dilarutkan dengan menggunakan sonicator. Kemudian ditambahkan 2,5 mL $\mathrm{H}_{2} \mathrm{SO}_{4} 4 \mathrm{~N}$ dan 2,5 mL KMnO 4 0,1 N. Setelah lima menit ditambahkan $1 \mathrm{~mL}$ KI $10 \%$ kemudian dititrasi dengan larutan $\mathrm{Na}_{2} \mathrm{~S}_{2} \mathrm{O}_{3} 0,1$ $\mathrm{N}$ dan digunakan larutan amilum $0,2 \%$ sebagai indikator. Perlakuan diatas dilakukan terhadap blanko tanpa menggunakan selulosa mikrokristal hasil isolasi.

\section{HASIL DAN PEMBAHASAN}

Selulosa mikrokristal dapat diperoleh melalui proses isolasi alfa selulosa dari ampas. Rendemen yang dihasilkan dari pembuatan selulosa mikrokristal dapat dilihat pada Tabel 1.

Tabel 1. Rendemen selulosa mikrokristal.

\begin{tabular}{ccc}
\hline $\begin{array}{c}\text { Ampas } \\
\text { Tebu } \\
(\text { gram })\end{array}$ & $\begin{array}{c}\text { Selulosa } \\
\text { Mikrokristal } \\
(\text { gram })\end{array}$ & $\begin{array}{c}\text { Rendemen } \\
\text { Selulosa } \\
\text { Mikrokrista } \\
1(\%)\end{array}$ \\
\hline 250 & 65,075 & 26,03 \\
\hline
\end{tabular}

Dari hasil Tabel 1 menyatakan bahwa randemen yang didapatkan untuk selulosa mikrokristal yaitu 26,03\%. Hasil ini lebih kecil jika dibandingkan dengan penelitian sebelumnya (Zulharmita, 2012) yang menghasilkan rendemen 28,6\%

\section{Hasil Pengujian Kadar Air Selulosa Mikrokristal}

Pengujian kadar air dilakukan dengai alat moisture balance. Hasil pengujian kadar air terdapat pada Tabel 2.

Hasil menunjukan bahwa kadar air dari selulosa mikrokristal yaitu sebesar $4,96 \%$ yang artinya selulosa mikrokristal hasil isolasi hanya mengandung air sebesar 4,96\%, kadar air tersebut masih dalam rentang persyaratan Handbook of Pharmaceutical Excipients yaitu kurang dari $5 \%$. 
Tabel 2. Hasil pengujian kadar air selulosa mikrokristal

\begin{tabular}{ccc}
\hline Pengujian & $\begin{array}{c}\text { Selulosa } \\
\text { Mikrokristal }\end{array}$ & $\begin{array}{c}\text { Syarat } \\
\text { (Rowe, 2009 }\end{array}$ \\
\hline Kadar Air(\%) & 4,96 & $<5$ \\
\hline
\end{tabular}

\section{Hasil Pemeriksaan Karakteristik Selulosa Mikrokristal}

Eksipien yang digunakan dalam sediaan farmasi harus memenuhi spesifikasi yang telah ditetapkan. Hasil pengujian selulosa mikrokristal dari ampas tebu dapat dilihat pada Tabel 3.

\section{Hasil Penentuan pH}

Penetuan $\mathrm{pH}$ dilakukan dengan $\mathrm{pH}$ meter digital. Pengukuran $\mathrm{pH}$ dengan cara mendispersikan selulosa mikrokristal $15 \%$ ke dalam aquadest (Thoorens, et al., 2015).

Tabel 4. menunjukkan selulosa mikrokristal hasil isolasi 6,9 Sampel tersebut berada pada rentang $\mathrm{pH}$ yang tertera pada literatur yaitu $\mathrm{pH}$ 5,0-7,5.
Tabel 4. Hasil pengamatan $\mathrm{pH}$

\begin{tabular}{lcc}
\hline Kualitas & $\begin{array}{c}\text { Selulosa } \\
\text { Mikrokristal }\end{array}$ & $\begin{array}{c}\text { Standar (Rowe, } \\
\text { 2009) }\end{array}$ \\
\hline $\mathrm{pH}$ & 6,9 & $5,0-7,5$ \\
\hline
\end{tabular}

\section{Hasil Penentuan Derajat Putih}

Pengujian derajat putih pada selulosa mikrokristal hasil isolasi diperlukan untuk menentukan kualitas warna serbuk. Warna serbuk yang akan dijadikan eksipien sebaiknya berwarna putih agar tidak mengganggu penampilan sediaan yang dihasilkan, selain itu juga mengikuti standar Handbook of Pharmaceutical Eksipients (2009) yang menyatakan bahwa selulosa mikrokristal harus berwarna putih. Selulosa mikrokristal hasil isolasi menghasilkan warna putih

\section{Hasil Penentuan Bilangan Permanganat}

Kualitas selulosa mikrokristal dapat ditentukan dengan pengujian bilangan

Tabel 3. Karakterisasi selulosa mikrokristal

\begin{tabular}{ccc}
\hline Karakterisasi & $\begin{array}{c}\text { Selulosa } \\
\text { Mikrokristal }\end{array}$ & Syarat (Rowe, 2009) \\
\hline KH & 4.95 & $<5$ \\
Kualitas serbuk & 6,9 & $5-7,5$ \\
a. Identifikasi Kualitatif & & \\
- Perubahan Warna & Violet Biru & Violet Biru \\
- Bentuk & Hablur & Hablur \\
- Warna & Putih & Putih \\
b. Organoleptis & & Tidak berbau \\
- Bau & Tidak berbau & Tidak berasa \\
- Rasa & Tidak berasa & \\
c. Kelarutan & & Tidak larut \\
- Air & Tidak larut & Tidak larut \\
- Alkohol 96\% & Tidak larut & Tidak larut \\
- HCl 2N & Tidak larut & Sukar Larut \\
- NaOH 1N & Sukar Larut & Tidak larut \\
- Eter & Tidak larut & Putih \\
Bilangan permanganat $(\%)$ & 4,052 & $<6$ \\
\hline
\end{tabular}


permanganat untuk mengetahui kadar lignin yang masih terkandung sebagai pengotor dalam sampel yang berpengaruh terhadap kemurniannya. Pengujian bilangan permanganat dilakukan terhadap pulp dengan kadar lignin dibawah 6\% (Standar Nasional Indonesia, 2008). Hasil perhitungan bilangan permanganat selulosa mikrokristal yaitu 4,052\%, hal tersebut menunjukkan bahwa selulosa mikrokristal yang dihasilkan masih memiliki kandungan lignin. Lignin yang terkandung dalam ampas tebu diurai melalui proses delignifikasi dan terlarut di dalam natrium hidroksida $25 \%$, sisa lignin dan karbohidrat yang tidak terurai sempurna dan masih tersisa di pulp.

\section{KESIMPULAN}

Berdasarkan penelitian yang telah dilakukan dapat disimpulkan bahwa selulosa mikrokristal dari ampas tebu memenuhi standar berdasarkan literatur dengan rendemen selulosa mikrokristal $26,03 \%$.

\section{UCAPAN TERIMA KASIH}

Penelitian ini didanai oleh Direktorat Riset dan Pengabdian Masyarakat (DRPM) Kementerian Riset Teknologi dan Pendidikan Tinggi (Kemenristekdikti) Tahun Anggaran 2019.

\section{Daftar Pustaka}

Bhimte, N. a and Tayade, P. T., 2007. Evaluation of microcrystalline cellulose prepared from sisal fibers as a tablet excipient: a technical note., AAPS PharmSciTech, 8(1), p. 8.

Carlin, B., 2008. Direct Compression and The Role of Filler-Binders. Dalam : Augsburger, L.L., Hoag, S.W. (Eds.). Pharmaceutical Dosage Forms: Tablets, Informa, pp. 173-216.

Cowd, M., 1991. Kimia Polimer. Bandung: ITB.

Håkansson, H. and Ahlgren, P., 2005. Acid hydrolysis of some industrial pulps: Effect of hydrolysis conditions and raw material, Cellulose, 12(2), pp. 177-183.

Hamisan, A. F. et al., 2009. Delignification of oil palm empty fruit bunch using chemical and microbial pretreatment methods.pdf, International Journal of agricultural Research, pp. 250-256.

Kementerian Kesehatan, R. I., 2013. Peraturan Menteri Kesehatan RI No. 71 Tahun 2013 Tentang Pelayanan Kesehatan Pada Jaminan Kesehatan Nasional.

Ma, X., Chang, P. R. and Yu, J., 2008. Properties of biodegradable thermoplastic pea starch/ carboxymethyl cellulose and pea starch/microcrystalline cellulose composites, Carbohydrate Polymers, 72(3), pp. 369-375.

Mersa, R. N., 2008. Karakterisasi Selulosa Mikrokristal dari Serbuk Gergaji Kayu Albasia sebagai Eksipien Tablet Metode Kempa Langsung, in. Jatinangor: Universitas Padjadjaran.

Mohamad Haafiz, M. K. et al., 2013. Isolation and characterization of microcrystalline cellulose from oil palm biomass residue, Carbohydrate Polymers. Elsevier Ltd., 93(2), pp. 628-634. 
Ohwoavworhua, F., Okhamafe, A. and Adelakun, T., 2009. Processing Pharmaceutical grade microcrystalline cellulose from groundnut husk: Extraction methods and characterization, International journal of Green Pharmacy, 3(2), pp. 97-104.

Patel, S., Kaushal, A. M. and Bansal, A. K., 2006, Compression Physics in the Formulation Development of Tablets, Critical Reviews ${ }^{\mathrm{TM}}$ in Therapeutic Drug Carrier Systems, 23(1), pp. $1-66$.

Rowe, R., Sheskey, P. and Quinn, M., 2009. Handbook of Pharmaceutical Excipients, Sixth edition, pp. 549-553.

Septiyani, R., 2011. Pengaruh Konsentrasi Dan Waktu Inkubasi Enzim Selulase Terhadap Kadar Gula Eduksi Ampas Tebu. Skripsi. Teknologi Hasil Pertanian. Universitas Lampung. $53 \mathrm{hlm}$.

Sun, J. X. et al., 2004. Isolation and characterization of cellulose from sugarcane bagasse, Polymer Degradation and Stability, 84(2), pp. 331-339

Thakur, M., 2014. Processing and Characterization of Natural Cellulose Fiber/Thermoset Polymer Composite, Charbohyd Polym, 109, pp. 102-117.

Umar, S.T., 2011. Pemanfaatan Serat Rami untuk Pembuatan Selulosa.Datinlitbang - BPP Kemenham RI. Tersedia di: http://www.balitbang.kemhan.go.id/?q =content/pemanfaatan-serat-ramiuntuk- pembuatan-selulosa [Diakses tanggal 9 Juni 2019]. 